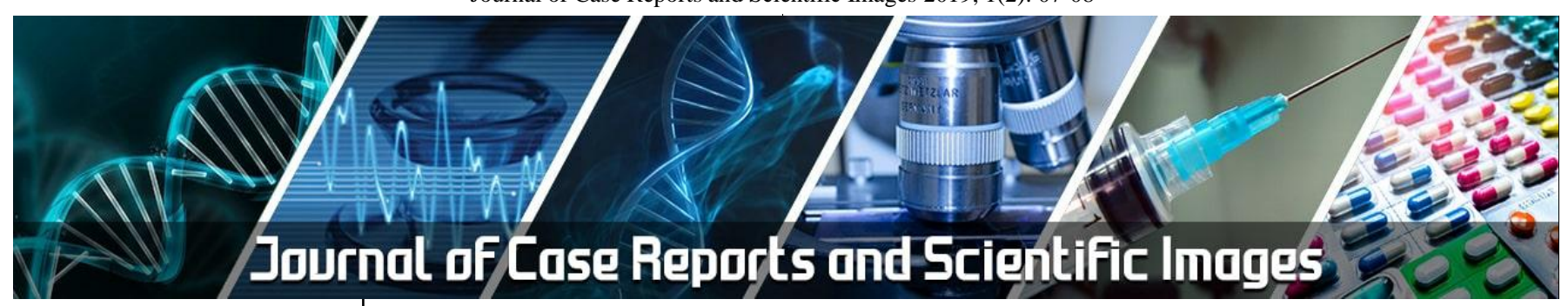

E-ISSN: 2708-0064 P-ISSN: 2708-0056 www.allcasereports.com JCRSI 2019; 1(2): 07-08 Received: 12-05-2019 Accepted: 15-06-2019

\section{Shusil Kumar}

Department of Scientific, Gandaki College of

Engineering and Science, Pokhara, Nepal
Corresponding Author: Shusil Kumar

Department of Scientific, Gandaki College of

Engineering and Science, Pokhara, Nepal

\section{Electrical cataract in 36 years old male patient- A case report}

\section{Shusil Kumar}

DOI: https://doi.org/10.33545/27080056.2019.v1.i2a.9

\section{Abstract}

Blindness due to cataract is terrific challenge for ophthalmologists on public health stance. We reported electrical cataract in 36 years old male patient.

Keywords: blindness, cataract, electrical

\section{Introduction}

Cataract is defined as opacity within the clear lens inside the eye that reduces the amount of incoming light and results in deterioration of vision. Natural lens is a crystalline substance and a precise structure of water and protein to create a clear passage for light. Cataract is often described as being similar to looking through a waterfall or waxed paper ${ }^{[1]}$.

Blindness due to cataract is terrific challenge for ophthalmologists on public health stance. It imposes great economic burden on people and surfeit to be handled by surgery alone. Alternatively, the preventive ophthalmology offers another approach to tackle the problem to identify factors, which might modify or simply delay the onset and progression of cataract by a period of 10 years, the number of cataract surgeries would drastically decrease by $45 \%$ or more. Therefore, identifying modifiable risk factors is of great importance from a public health perspective. The better understanding of causes can definitely have great impact in its management, as elimination of causes is the main key to eradicate any disease ${ }^{[2]}$.

Electric trauma producing cataract is rare, however, there have been few cases reported in literature. Such cataracts are known to develop several months later and then progress with startling rapidity. The majority of cases respond well to surgery, but final visual acuity depends on the other ocular damage due to electrical current. The need for awareness of the possibility of this complication and screening of all cases of electrical injuries is stressed ${ }^{[3]}$. We reported a case of electrical cataract in 36 years old male patient.

\section{Case Report}

A 53 years old male patient reported to eye department with diminution of vision in right eye since 6 months. History revealed an injury to right eye from a high-voltage electric cable 2.4 years ago. He had undergone right eye cataract surgery with intraocular lens implantation 6 months back.

On examination, his best corrected visual acuity on Snellen's chart was 6/9 in right eye. On slit lamp examination lids, conjunctiva, cornea and pupils showed no abnormality in eye. Right eye had a posterior chamber intraocular lens. Also a central cortical opacity with shrunken anterior capsule was seen. There was a complete cleavage of cortex and a separation was visible in retro illumination. Fundus examination was unremarkable in right eye. Phaco-emulsification with foldable hydrophobic posterior chamber IOL in the capsular bag was done under peribulbar anesthesia in right. Postoperatively the recovery was uneventful.

\section{Discussion}

Cataract develops from a variety of reasons. Human cataract formation is mostly considered to be a multifactorial disease. Most of them develop with their specific etiologies and can be diagnosed through it, e.g., posterior (classically due to steroid use) and anterior (common senile cataract). Genetically determined cataract is due to an anomaly in the chromosomal 
pattern of the individual. About one third of all congenital cataracts are hereditary. It may occur with or without microphthalmia, aniridia, anterior chamber developmental anomalies, retinal degenerations, other multisystem genetic disorders such as chromosome abnormalities, Lowe syndrome or neurofibromatosis type. PITX3 gene is reported to be responsible for some inherited cataracts in anterior segment mesenchymal dysgenesis ${ }^{[4]}$. We reported a case of cataract in 36 years old male patient.

High voltage electric burns can cause various ocular injuries in the form of conjunctival hyperemia, corneal opacities, uveitis, miosis, spasm of accommodation, cataract, retinal edema, papilledema, chorio-retinal necrosis/atrophy, retinal detachment and optic atrophy, macular edema and macular cysts or holes. The amount of energy delivered depends on the resistance between two points. It is known that lower the resistance greater the internal injuries, higher the resistance greater the surface burns ${ }^{[5]}$.

Verma et al. ${ }^{[6]}$ reported a case in 25 years old male, who developed Electrical Cataract in both eyes after a shock from high voltage. Although electrical cataract due to high voltage or lightning is rare, they may still occur after industrial or home electric accidents. Even if cataract extraction with intraocular lens implantation is successfully performed, the final visual acuity depend on other ocular damage due to the electric current.

The incidence of cataract reported in patients with electrical injuries varies from $0.7 \%$ to $8.0 \%{ }^{[7]}$. This is probably due to differences in the voltage and duration of action of the current, the distance of the area of contact from the eye, the extent of the surface contact, and the direction taken by the current in the body. The strength of electrical current causing cataract formation varies from 220 to 80000 volts. The cataract may develop immediately after injury or be delayed a few days; the latency varies from 1 to 18 months, although a latent period of 11 years has also been reported. If the point of contact is on one side and the lens changes are bilateral, the cataract initially forms in the eye on the affected side (closest to the contact point) and later in the contralateral eye ${ }^{[8]}$. The interval between cataracts occurring in the 2 eyes can vary from 3 weeks to 2 years. High voltage electric burns can cause various ocular injuries and may manifest in the form of conjunctival hyperemia, corneal opacities, uveitis, miosis, spasm of accommodation, cataract, retinal edema, papilloedema, chorio-retinal necrosis/atrophy, retinal detachment and optic atrophy. Choroidal rupture, optic neuritis and retinal detachment may also be seen. Macular edema may progress to macular cysts or holes [9]

Madan et al. ${ }^{[10]}$ reported a rare case of a 15 years young boy having bilateral anterior sub-capsular cataracts caused by high-voltage electrocution in a young man who regained normal vision after surgery in both eyes. Bilateral Phacoemulsifiation with foldable hydrophobic lens [PCIOL] in capsular bag was done.

\section{Conclusion}

Authors found that proper surgical management of electric cataract will result in a good visual rehabilitation if the eye has no additional damage.

\section{References}

1. Raina UK, Tuli D. Bilateral electric cataract. Br J Ophthalmol. 1999; 83:1091.
2. Long JC. Electric cataract: report of three cases. Am J Ophthalmol. 1966; 61(5 Pt 2):1235-1239.

3. Riaz Khan M, El Faki HMA. Acute cataract and optic atrophy after highvoltage electrical injury. Eur J Plast Surg. 2008; 31(2):73-74.

4. Von Bahr G. Electrical injuries. Ophthalmologica. $1969 ; 158: 109-117$.

5. Weeks AW, Alexander L. The distribution of current in the animal body. J Indust Hyg \& Toxicol. 1939; 21:517-520.

6. Saffle JR, Crandall A, Warden GD. Cataracts a long term complication of electrical injury. J Trauma. 1985; 25(1):17-21.

7. Verma A. Electric cataract: a case report. MOJ Biol Med. 2018; 3(5):201-202.

8. McCarty CA, Nanjan MB, Taylor HR. Attributable risk estimates for cataract to prioritize medical and public health action. Invest Ophthalmol Vis Sci. 2000; 41:3720- 25.

9. Kupfer C. The conquest of cataract: A global challenge. Trans Ophthalmol Soc UK 1985; 104:01- 10.

10. Gupta VB, Rajagopala M, Ravishankar B. Etiopathogenesis of cataract: An appraisal. Indian $\mathbf{J}$ Ophthalmol. 2014; 62:103-10.

11. Madan A, Deshmukh M, Chaukhe BA. Bilateral electric cataract: A rare case report. Indian Journal of Clinical and Experimental Ophthalmology. 2017; 3(1):115-6. 